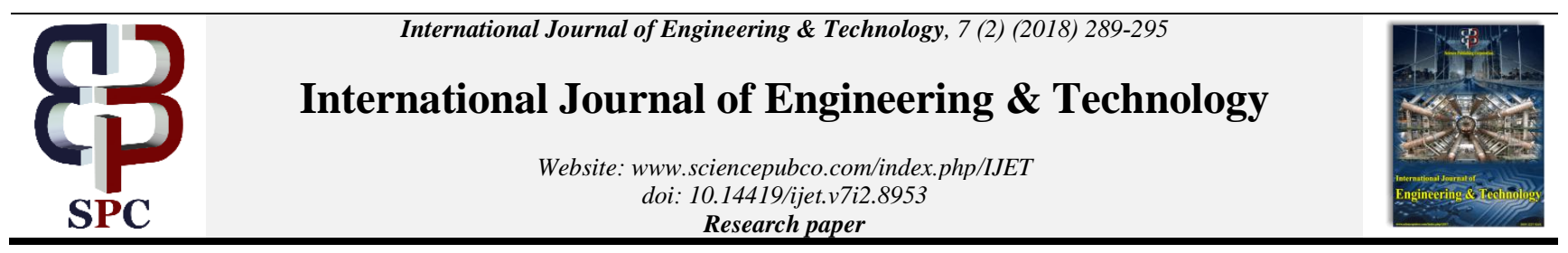

\title{
A theoretical model for predicting the vibration response of outer race defective ball bearing
}

\author{
Samir Shaikh ${ }^{1 *}$, Sham Kulkarni ${ }^{2}$ \\ ${ }^{1}$ Department of Mechanical Engineering, PG Scholar, SKN Sinhgad C.O.E, Korti, \\ Pandharpur, Solapur University, Maharashtra, India \\ ${ }^{2}$ Department of Mechanical Engineering, Faculty of Engineering, \\ SKN Sinhgad C.O.E, Korti, Pandharpur, Maharashtra, India \\ *Corresponding author E-mail: samirshaikh2693@gmail.com
}

\begin{abstract}
The theoretical model with 2 degree-of-freedom system is developed for predicting the vibration response and analyze frequency properties in an extended type defective ball bearing. In the mathematical formulation, the contact between the races and rolling element considered as non-linear springs. The contact forces produced during the collaboration of rolling elements are obtained by utilizing Hertzian contact deformation hypothesis. The second order nonlinear differential equation of motion is solved using a state space variable method with the help of MATLAB software and the vibration acceleration response of the defective ball bearing presented in the frequency spectrum. The effects of variation in speed and size of the defect on characteristic frequency of extended fault on the outer raceway of the ball bearing have been investigated. The theoretical results of the healthy (non defective) and defective bearing are compared with each other.
\end{abstract}

Keywords: Ball bearing; Defect; Defect frequency; Hertzian contact theory; Vibration.

\section{Introduction}

Source of vibration in any machine is unbalanced, misalignment, faulty gear, and faulty bearing etc. Out of these, the rolling element bearing is the important machine element. If a bearing fails, the whole production line is affected and it will also affect the productivity. Hence it is very crucial to monitored regularly health of the rolling element bearing. The defects arise mostly due to incorrect design, mistaken manufacturing and mounting, misalignment of bearing, improper lubrication, excessive loading, fatigue, wear etc. The defect is parted into two types such as localized defects and distributed defects. Because of fatigue in the rolling element bearing appear wisecracks, small holes, and spall on the rolling surfaces that are such defects is a localized defect. like wisecracks, pits, and spall on rolling surfaces caused by fatigue. The regularly occurring failure is the crack in the bearing races because of the fatigue caused to spread over the bearing surface until a piece of metal separate from the surface creating a small hole. This defect increase if the bearing is loaded too heavily or also existing impact loads during their functioning.

The distributed defect is mainly exhibited during mistaken manufacturing, improper assembly, and wear. Bearing frequently develop a localized defect in the raceways, rollers, and cage. The periodic impact is generated when the ball passes upon these defects with the exception of cage defects. This will cause conversion of localized defects into the distributed defects. The contact force differs between the rolling elements (balls) and raceways an accelerating vibration level because of defects. Hence, the study of vibration response for the defective bearing is most important to check the quality of a bearing or condition monitoring.

Many researcher works had done in the area of vibration response in the ball bearing, as bearing rotates, the ball changes their positions. R.K Purohit and K. Purohit [1] Studied, dynamic analysis of ball bearing with the effect of preload and number of balls and also study the radial and axial vibrations of the rigid shaft supported bearing are studied. A book by Harris [2] discusses a detailed study on different types of defects those occur on the surface of the bearing. P. D. McFadden and J. D. Smith [3][4] Developed, a mathematical model to describe the vibration response by single point defect and multiple defects on the inner race of rolling element bearing under constant radial load. N. Tandon and A. Choudury [5] [6] Studied for predicting the vibrational characteristic frequencies of the rolling element bearing and the vibration response due to a point defect on raceway or on one of the rolling elements under radial load. An amplitude of the outer race defect is found to be quite high in comparison to inner race defect and the rolling element defect. Also found amplitude level increases with increase in load. also developed, a mathematical model to predict the accelerating vibration due to distributed defects in various bearing elements under radial load. N. Tandon and A. Choudury et al. [7] Proposed accelerating amplitude response of the rolling element bearing in a rotor-bearing system for a point defect under a pure radial load. M. S. Patil, et al. [8] Studied theoretical model to make the ball bearing vibration know in advance when the effect of a localized defect in their functioning. V. N. Patel, et al. [9] Studied the vibration response of the deep groove ball bearings with single and various imperfections on the bearing raceway. The comparative study of vibration response for the cases having a single and two defects on raceways and this results are higher amplitude response with two defects. Jairo A. Grajales, et al. [10] Developed mathematical model of the ball bearing having localized defect on the outer raceway and the results obtained from the model validate with experimental results. In this study bearing is assumed as mass-spring-damper system considering each ball as a contact spring-damper pair. V. V. Nagale, et al. [11] studied a mathematical 
model to determine the sensitivity of vibration signals for a localized defects and to find an effective number of balls in the ball bearing. N. Sawalhi, R. B. Randall [12] Modelling gear and bearing the situation in the presence of faults as an extended defect on the raceway of rolling element bearings. Dick Petersen, et al. [13] analyses contact forces in defective bearing, stiffness variation respective rolling elements, and also studied vibrations in radially loaded double row ball bearing with extended raceway defects. Most researchers focused their attention on the detection of localized defects in the bearing whereas less attention is given to an extended defect. However, when local defect grows, it becomes extended one and tends to spread over the track of the bearing race. There is a necessity to implement effective diagnosis of an extended fault in the ball bearing. It is a need to anticipate the vibration response of an extended imperfection on the outer raceway of the ball bearing by utilizing the Newton's law of motion.

\section{Mathematical model of system}

A bearing is chosen with the end goal that it ought to be effortlessly amassed and disguise. A single row deep groove ball bearing is to be chosen for development of theoretical model according to the low-speed application. A characteristic value such as inner diameter, outer diameter, depth of the groove, could be known. Consider a 2 degree-of-freedom non-linear spring-mass system, in which the outer race is settled in an unbending support and the inner race is settled inflexibility with the motor shaft. Elastic deformation amongst raceways and rolling elements delivers a non-linear phenomenon between force and deformation, which is obtained by the Hertz contact theory. The rolling element bearing is considered as non-linear contact spring as shown in above figure 1
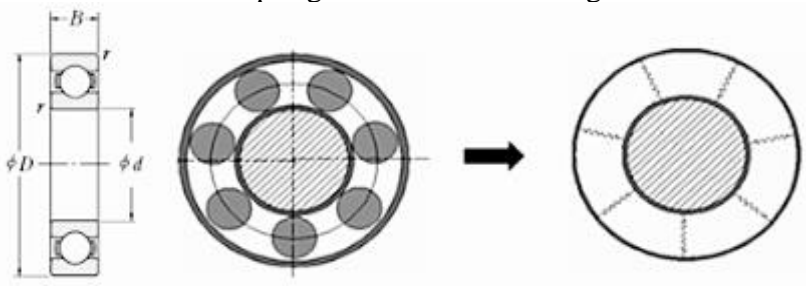

Fig. 1: Rolling element replaced by non-linear spring

While building up the model, the assumptions considered are mentioned below:

1. In the ball bearing model rolling elements (balls) are equispaced.

2. There is no Slipping of the balls.

3. The motion of races and balls present in the plane of the bearing only.

4. The outer race is unbendingly settled with bearing housing.

5. There is no elastic deformation of an inner and outer race.

6. There is no change in temperature of the selected ball bearing.

Table 1 Geometric Properties of Bearing.

\begin{tabular}{ll}
\hline Parameter & Value \\
\hline Stiffness of bearing $(\mathrm{K})$ & $8.5471^{*} 10^{\wedge} 5\left(\mathrm{~N} / \mathrm{m}^{3 / 2}\right)$ \\
Bearing outside diameter $(\mathrm{D})$ & $85 \mathrm{~mm}$ \\
Bearing bore diameter $(\mathrm{d})$ & $30 \mathrm{~mm}$ \\
Ball diameter $\left(\mathrm{d}_{\mathrm{b}}\right)$ & $17.463 \mathrm{~mm}$ \\
No of ball $(\mathrm{z})$ & 7 \\
Bearing width $(\mathrm{B})$ & $23 \mathrm{~mm}$ \\
Pitch diameter $\left(\mathrm{P}_{\mathrm{d}}\right)$ & $57.5 \mathrm{~mm}$ \\
Inner race groove radius $\left(\mathrm{r}_{\mathrm{gi}}\right)$ & $9.168 \mathrm{~mm}$ \\
Outer race groove radius $\left(\mathrm{r}_{\mathrm{go}}\right)$ & $9.255 \mathrm{~mm}$ \\
Damping coefficient $(\mathrm{c})$ & $200 \mathrm{Ns} / \mathrm{m}$ \\
Mass of Bearing $(\mathrm{M})$ & $800 \mathrm{gm}$ \\
Radial clearance $\left(\mathrm{C}_{\mathrm{r}}\right)$ & $0.013 \mathrm{~mm}$ \\
\hline
\end{tabular}

Different expressions for developing the bearing model are derived from a book by Harris [2], for calculating the contact forces in the bearing using the Hertz contact theory of deformation. Geometric
Properties of the bearing shown in Table 1. These properties are required for computing the contact forces and the figuring bearing load distribution as for the precise position of the ball.

\subsection{Analysis of defective ball bearing}

While developing the numerical model, the defect on the races is represented like a sinusoidal wave. The location of the defect $(\theta)$ is at 45 degrees from the $\mathrm{X}$-axis.

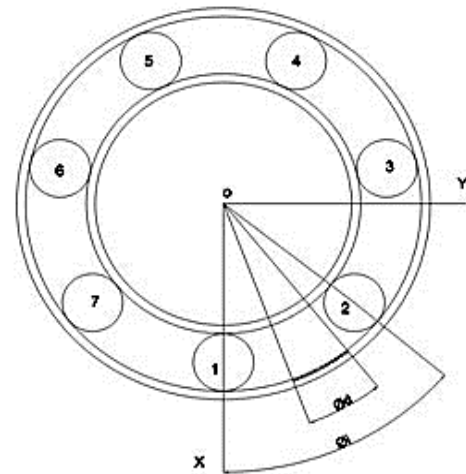

Fig. 2: Defective ball bearing

An extended defect is spread similarly both sides from the focal point of the defect location. The ball goes through the defect accordingly the additional deflection $\left(D_{d e f}\right)$ for the travel of the ball in the defective region of the outer race can be determined,

$$
\begin{aligned}
& D_{\text {def }}=R_{a} * \sin (\pi / \varphi) *(\theta i-\theta) \\
& \varphi=N_{w} *\left(\omega_{\mathrm{c}} * \mathrm{t}+\emptyset_{d} * \frac{\mathrm{i}-1}{\mathrm{z}}\right)
\end{aligned}
$$

Where Ra is a depth of the defect, $\varphi$ is an overall size of the defect, $\emptyset_{\mathrm{d}}$ is the size of defect span in degree, $\omega_{\mathrm{c}}$ is cage velocity, $\mathrm{N}_{\mathrm{w}}$ number of waves, $\theta i$ is the angular distance between each ball in degree, $\theta$ is the location of defect from $\mathrm{X}$-axis in degree. In general, the deflection of ball located at any angular position given by,

$$
\delta=\left[(\mathrm{x} \cos (\theta \mathrm{i})+\mathrm{y} \sin (\theta \mathrm{i}))-\left(\mathrm{C}_{\mathrm{r}}\right)\right]
$$

Where $\theta \mathrm{i}$ is a location of the ball, $\mathrm{x}$ is deflection along the $\mathrm{X}$-axis, $\mathrm{y}$ is deflection along the $\mathrm{Y}$-axis, $\mathrm{Cr}$ is radial clearance and the contact force is,

$$
\mathrm{F}=\mathrm{K} *[\delta]^{3 / 2}
$$

The contact stiffness of the ball is calculated by using following equation (5)[2]

$$
K=\left[\frac{1}{\left(\frac{1}{k_{i}}\right)^{\frac{1}{n}}+\left(\frac{1}{k_{0}}\right)^{\frac{1}{n}}}\right]^{n}
$$

Contact stiffness of inner race $\left(\mathrm{k}_{\mathrm{i}}\right)$ and Contact stiffness of outer race $\left(\mathrm{k}_{0}\right)$ also calculated from the geometrical properties of the ball bearing.

The Hertzian forces arise only when there is contact deformation when spring is performed only in compression. The total restoring force along the $\mathrm{X}$-and $\mathrm{Y}$-axis is obtained.

$$
\begin{aligned}
& \mathrm{Fx}=\sum_{\mathrm{i}=1}^{\mathrm{z}} \mathrm{K} *\left[(\mathrm{x} \cos (\theta \mathrm{i})+\mathrm{y} \sin (\theta \mathrm{i}))-\left(\mathrm{C}_{\mathrm{r}}\right)\right]^{3 / 2} * \cos (\theta \mathrm{i}) \\
& \mathrm{Fy}=\sum_{\mathrm{i}=1}^{\mathrm{z}} \mathrm{K} *\left[(\mathrm{x} \cos (\theta \mathrm{i})+\mathrm{y} \sin (\theta \mathrm{i}))-\left(\mathrm{C}_{\mathrm{r}}\right)\right]^{3 / 2} * \sin (\theta \mathrm{i})
\end{aligned}
$$


For calculating the contact forces in the defective bearing we required to account this Ddef is an additional deflection in the equation (3) and (4) become,

$$
\begin{gathered}
\mathrm{F}_{\mathrm{XD}}=\sum_{\mathrm{i}=1}^{\mathrm{z}} \mathrm{K}\left[(\mathrm{x} \cos (\theta \mathrm{i})+\mathrm{y} \sin (\theta \mathrm{i}))-\left(\mathrm{C}_{\mathrm{r}}\right.\right. \\
\left.\left.\left.+D_{\mathrm{def}}\right)\right)\right]^{3 / 2} \cos (\theta \mathrm{i}) \\
\mathrm{F}_{\mathrm{YD}}=\sum_{\mathrm{i}=1}^{\mathrm{z}} \mathrm{K}\left[(\mathrm{x} \cos (\theta \mathrm{i})+\mathrm{y} \sin (\theta \mathrm{i}))-\left(\mathrm{C}_{\mathrm{r}}\right.\right. \\
\left.\left.\left.+D_{\mathrm{def}}\right)\right)\right]^{3 / 2} \sin (\theta \mathrm{i})
\end{gathered}
$$

Angular distance between each ball in the bearing in legree $(\theta \mathrm{i})$

$$
\theta i=\omega_{c} * t+\frac{2 \pi(z-i)}{z}
$$

Angular velocity of the shaft $\left(\omega_{\mathrm{s}}\right)$ will be

$\omega_{\mathrm{s}}=\frac{2 \pi \mathrm{Ns}}{60}$

Angular velocity of the cage $\left(\omega_{c}\right)$ will be

$$
\omega_{\mathrm{c}}=\frac{\omega_{\mathrm{s}}}{2}-\left(1-\frac{\mathrm{d}_{b}}{p_{d}} * \cos (\alpha)\right)
$$

Ns is the speed of the shaft, $\omega_{c}$ is angular velocity of the cage in $\mathrm{rad} / \mathrm{s}, \omega_{\mathrm{s}}$ is angular velocity of the shaft in $\mathrm{rad} / \mathrm{s}$.

\subsection{Equation of motion}

Taking $\mathrm{x}$ and $\mathrm{y}$ as the displacement of the $\mathrm{X}$ and $\mathrm{Y}$ directions, the governing equation for a two degree of freedom system is formed.

$$
\begin{gathered}
\mathrm{M} \ddot{\mathrm{x}}+\mathrm{c \dot {x }}+\sum_{\mathrm{i}=1}^{\mathrm{z}} \mathrm{K}\left[(\mathrm{x} \cos (\theta \mathrm{i})+\mathrm{y} \sin (\theta \mathrm{i}))-\left(\mathrm{C}_{\mathrm{r}}+\mathrm{Ddef}\right)\right]^{3 / 2} * \operatorname{co} \\
=\mathrm{W}+\mathrm{Fu} * \cos (\theta) \\
\left.\mathrm{M} \ddot{\mathrm{y}}+\mathrm{c} \dot{\mathrm{x}}+\sum_{\mathrm{i}=1}^{\mathrm{z}} \mathrm{K}\left[(\mathrm{x} \cos (\theta \mathrm{i})+\mathrm{y} \sin (\theta \mathrm{i}))-\left(\mathrm{C}_{\mathrm{r}}+\text { Ddef }\right)\right)\right]^{3 / 2} \\
* \sin (\theta \mathrm{i})=0
\end{gathered}
$$

Where $M$ is mass of ball bearing, $F_{X D} \& F_{Y D}$ is a resolving forces for the presence of a defect in the bearing race and $\mathrm{Fu}=\mathrm{m}^{*} \mathrm{r}^{*} \omega^{2}$ is an unbalanced force.

Equation (10) and (11) are a second-order nonlinear differential equation. A solution of these equations obtained by converting into first order differential equation using state space variable method. A computer program is developed to obtain the solution. Using the state space method equation (10) are solved in MATLAB and frequency in $\mathrm{X}$ and $\mathrm{Y}$ directions and their amplitude are obtained.

\subsection{Solution for equation of motion}

For mathematical solutions, the initial conditions and step sizes are very important for progressive and monetary computational solutions. Especially for nonlinear systems, different starting conditions mean an entirely unexpected system and subsequently unique solutions. Improper initial conditions can also cause a larger computation time or sometimes wrong results obtained. The larger the time step, the faster the computation time. Then again, the time step should be small enough to achieve an adequate accuracy. Additionally, little time steps can build truncation errors. In this way, an advancement ought to be made between them. At time $t=0$ the following assumptions are made:
1. The initial displacements and velocities of the shaft are set to be the following values: $x=10^{-5} \mathrm{~m}, y=10^{-5} \mathrm{~m}$. The velocities are assumed to be zero: $\dot{x}=0, \dot{y}=0$. The initial accelerations are obtained using Equation (13) and (14).

2. The initial displacements of the ball centers in radial direction are set to be $C_{r}=0.0013 \mathrm{~mm}$; and acceleration is $x_{0}=1 \mathrm{~m} / \mathrm{s}^{2}$, $\mathrm{y}_{\mathrm{o}}=1 \mathrm{~m} / \mathrm{s}^{2}$.

3. For each ball in the ball bearing considered as same deflection and velocities.

4. Assume the contact stiffness for each ball are same while modeling the solution for the defective and healthy bearing.

\subsubsection{Solution procedure:}

A solution of equations using the simulation program can be carried out in the following order:

a. Read all necessary data for the ball bearing system.

b. All the variables (i.e. $\theta_{i}, \delta^{*}, \delta_{\max }$, etc.) are calculated using the above stated initial conditions.

c. Calculate the contact stiffness factor (K) using equation (5).

d. The maximum contact force is calculated by using equation (4)

e. The shaft angular velocity $\left(\omega_{s}\right)$ cage angular velocity $\left(\omega_{c}\right)$ is calculated for the respective speed of the rotating shaft.

f. The new contact forces are obtained in $\mathrm{x} \& \mathrm{y}$-direction from equation (6) and (7) if a ball in the defective region then calculates the equation (8) and (9).

g. The total restoring forces in the $x, y$ directions are obtained.

$h$. The equations of motion (i.e., equation (13) \& (14)) are solved to find an acceleration response

i. Steps (e to h) are repeated for the required speed of the shaft.

j. The results are recorded to show the frequency response.

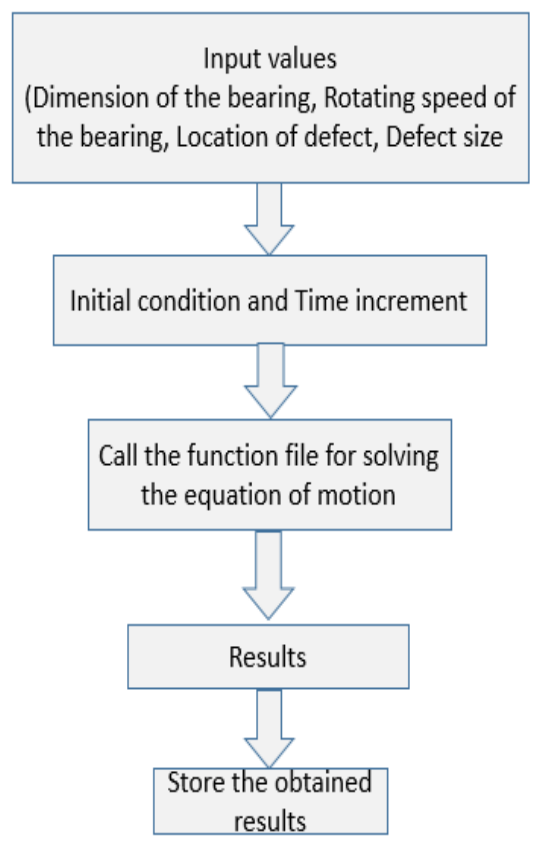

Fig. 3: Block diagram of a program

\section{Results and discussion}

The results for peak amplitudes of vibration for each variation of the running parameter in different shaft speeds and defect size are to be analyzed in this study. The nonlinear equations are solved to obtain an acceleration response of healthy and defective ball 
bearing. In order to get the outcomes, the source of inputs is shown in Table 1.

\subsection{Vibration response of healthy bearing}

The time step for the investigation is considered at the time required for 0.1 degrees of rotation. For the shaft speed of 300 RPM, 600 RPM, 900 RPM, 1200 RPM the initial displacements set to the values: $x=10^{-5} \mathrm{~m}$ and $\mathrm{y}=10^{-5} \mathrm{~m}$. The starting velocities are considered to be zero. For a shaft speed, Ns=300 RPM

Shaft speed, $\omega_{\mathrm{s}}=\frac{2 \pi \mathrm{Ns}}{60}=31.41 \mathrm{rad} / \mathrm{s}$

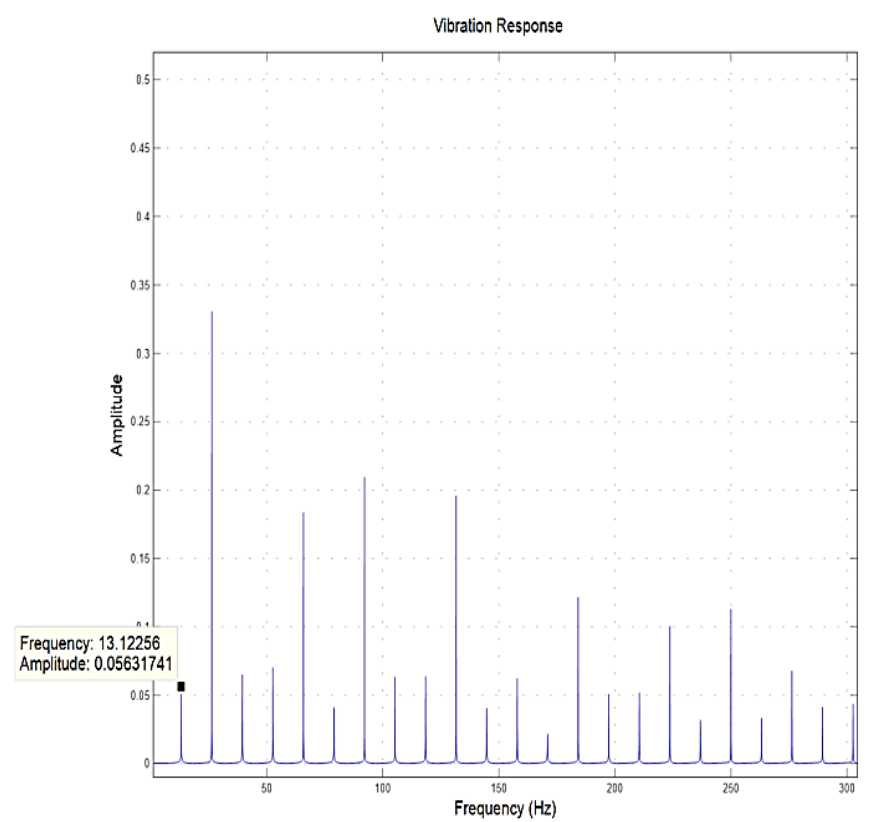

(a)

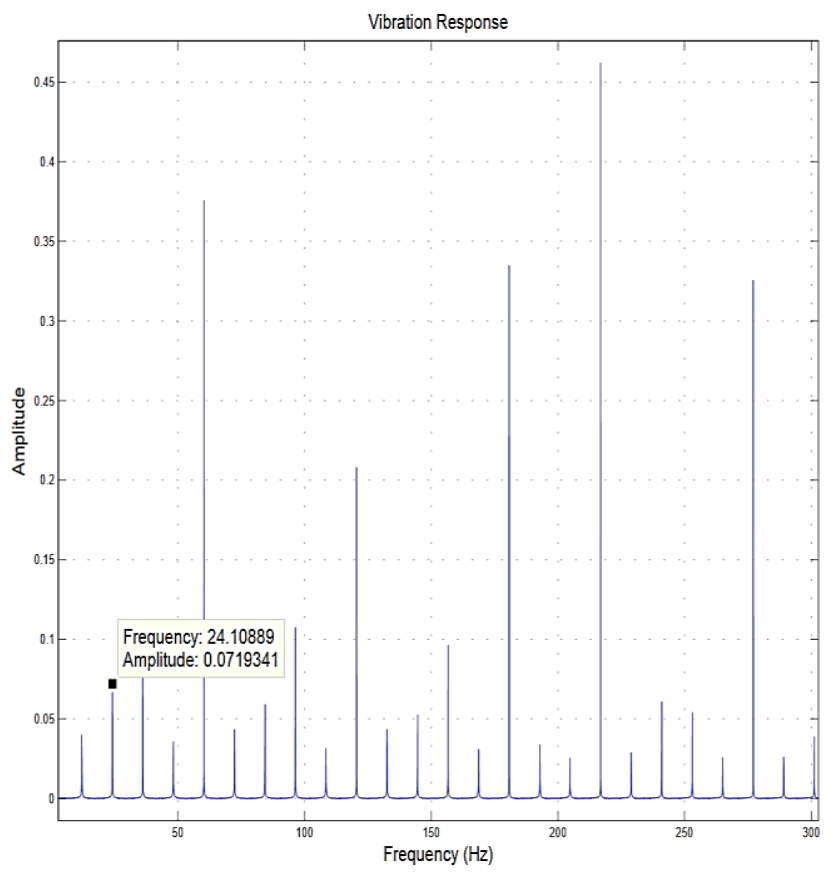

(b)
Shaft frequency, $\mathrm{Fs}=\mathrm{Ns} / 60=5 \mathrm{~Hz}$

Cage speed, $\omega_{\mathrm{c}}=\frac{\omega_{\mathrm{s}}}{2}-\left(1-\frac{\mathrm{d}_{b}}{p_{d}} * \cos (\alpha)\right)=10.85 \mathrm{rad} / \mathrm{s}$

Ball pass frequency outer $(\mathrm{BPFO})=\frac{\mathrm{ZNs}}{2 * 60}-\left(1-\frac{\mathrm{d}_{b}}{p_{d}} * \cos (\alpha)\right)$

$$
=12.075 \mathrm{~Hz} \text {. }
$$

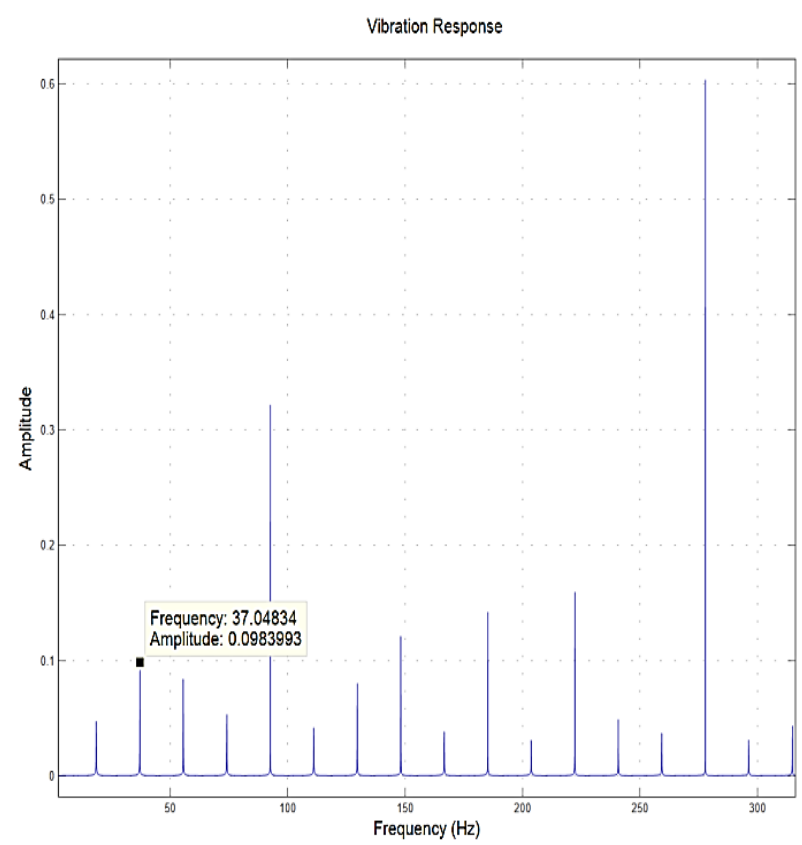

(c)

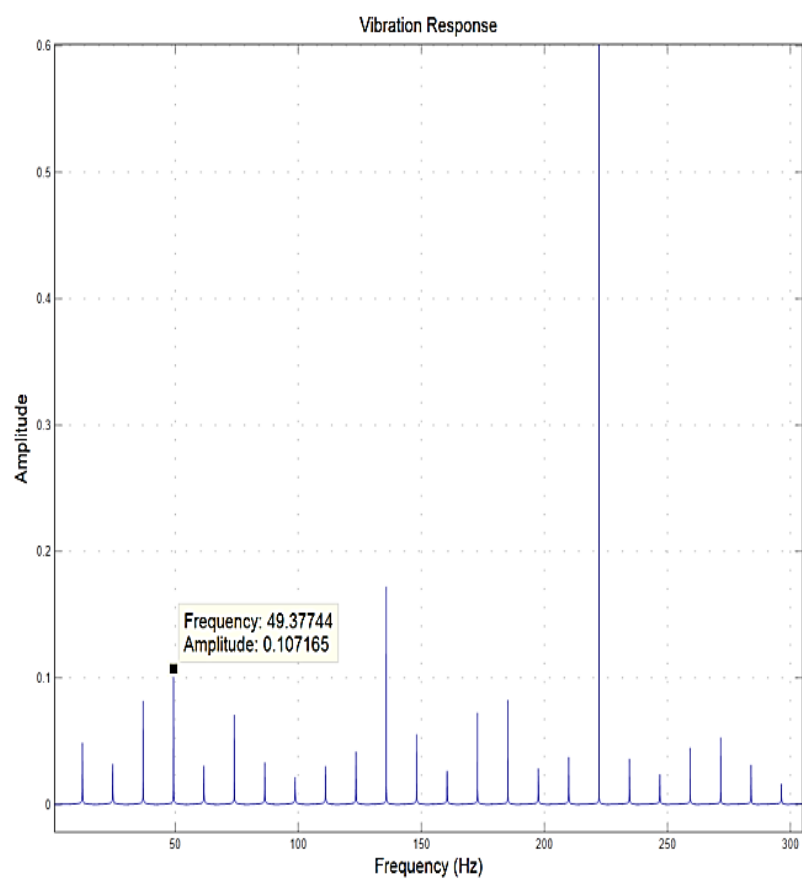

(d)

Fig. 3: Vibration response of healthy bearing at (a)300; (b) 600; (c) 900; (d) 1200 RPM

Above fig. 3 shows the vibration amplitude of the healthy bearing is obtained as $0.0563 \mathrm{~m} / \mathrm{s}^{2}, 0.07193 \mathrm{~m} / \mathrm{s}^{2}, 0.0983 \mathrm{~m} / \mathrm{s}^{2}, 0.1071 \mathrm{~m} / \mathrm{s}^{2}$ at 300, 600, 900, 1200 RPM respectively. There is a significant increase in the amplitude of vibration with an increasing the speed of the shaft. The peaks at BPFO have seen in the frequency spectra is $13.12 \mathrm{~Hz}, 24.10 \mathrm{~Hz}, 37.04 \mathrm{~Hz}, 49.37 \mathrm{~Hz}$. From the theoretical model while calculating ball pass frequency outer (BPFO) are $12.075 \mathrm{~Hz}, 24.15 \mathrm{~Hz}, 36.225 \mathrm{~Hz}, 48.30 \mathrm{~Hz}$ for the speed 300,600 , 900, 1200 RPM respectively. The calculated ball pass frequency outer (BPFO) and the peaks generated in the frequency spectra are very close to each other this is clearly shown in fig. 3 . 


\subsection{Vibration response of the defective ball bearing}

The defect in the bearing is modeled as a sinusoidal wave. The defect size corresponding to the length of the defect in the direction of the motion. The depth of defect is taken as $4 \mu \mathrm{m}$ and the location of the defect $(\theta)$ is at 45 degrees. An extended defect is spread equally both sides of the center of defect location. Vibration

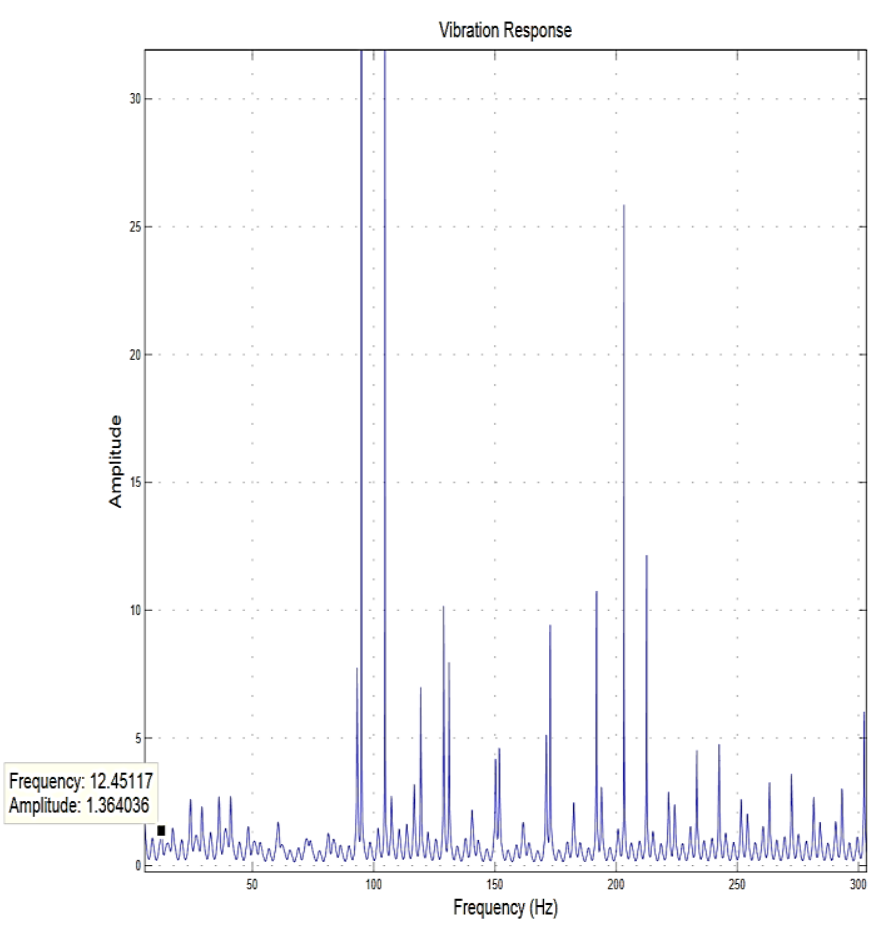

(a)

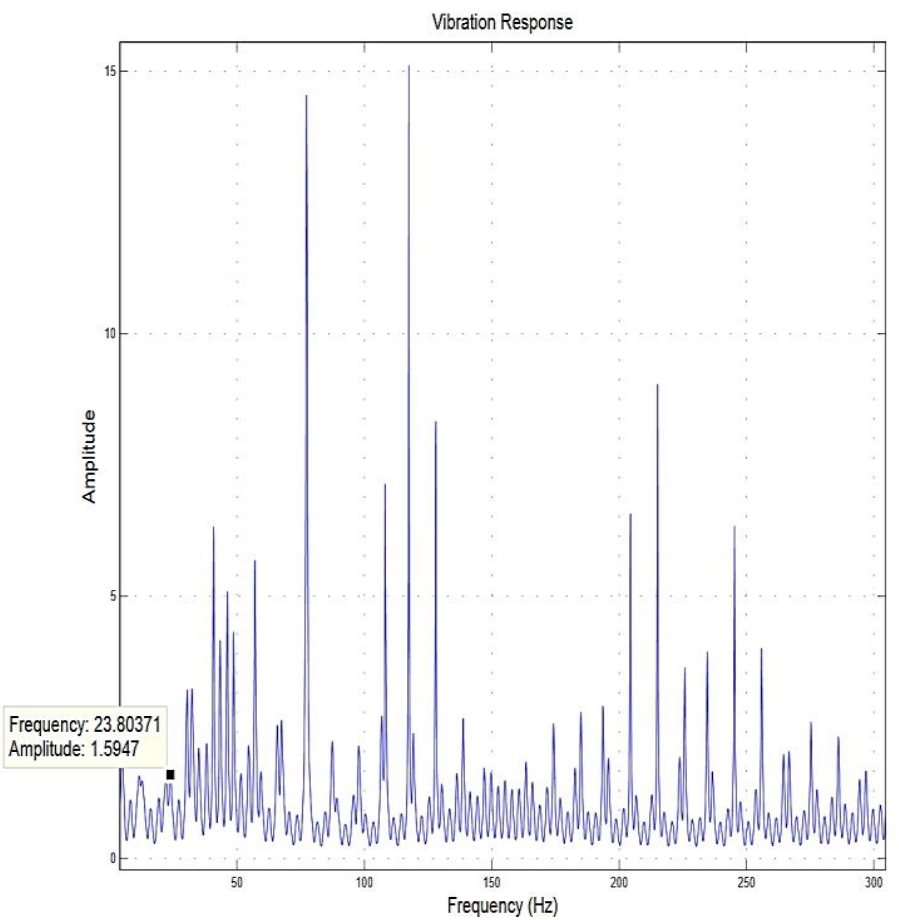

(b) response from ball bearing due to the constant radial load for the defective bearing (defect sizes 10-degree \& 20-degree) with varying speed (300 to $1200 \mathrm{RPM}$ ) is simulated by using MATLAB.

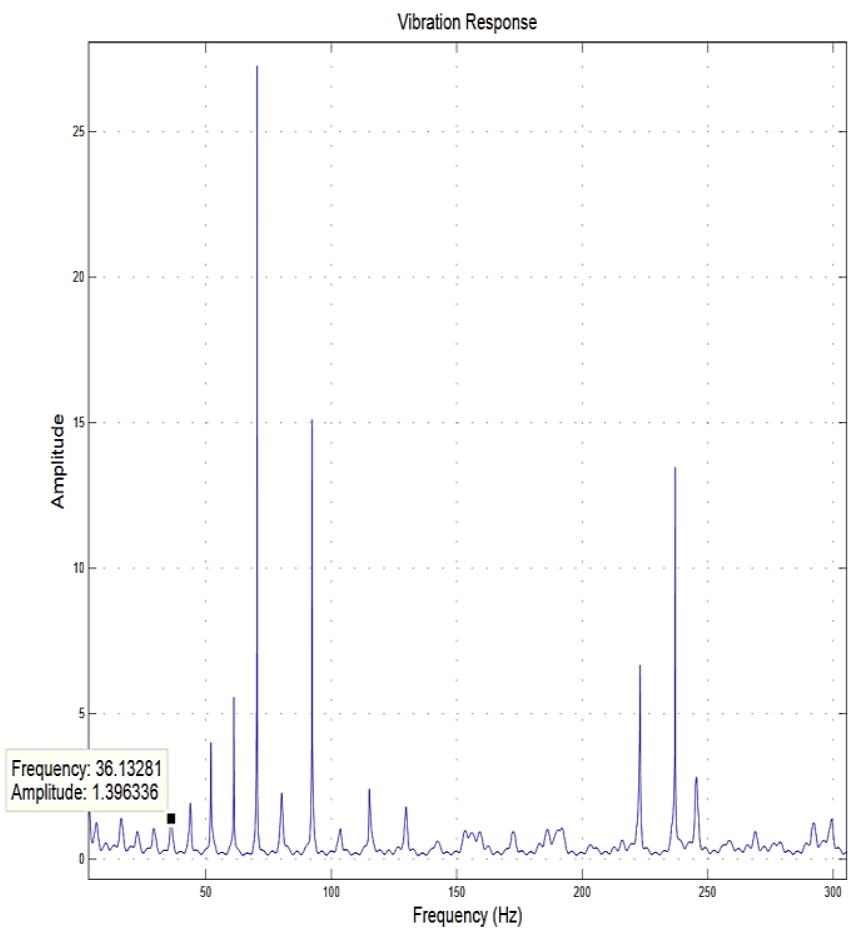

(c)

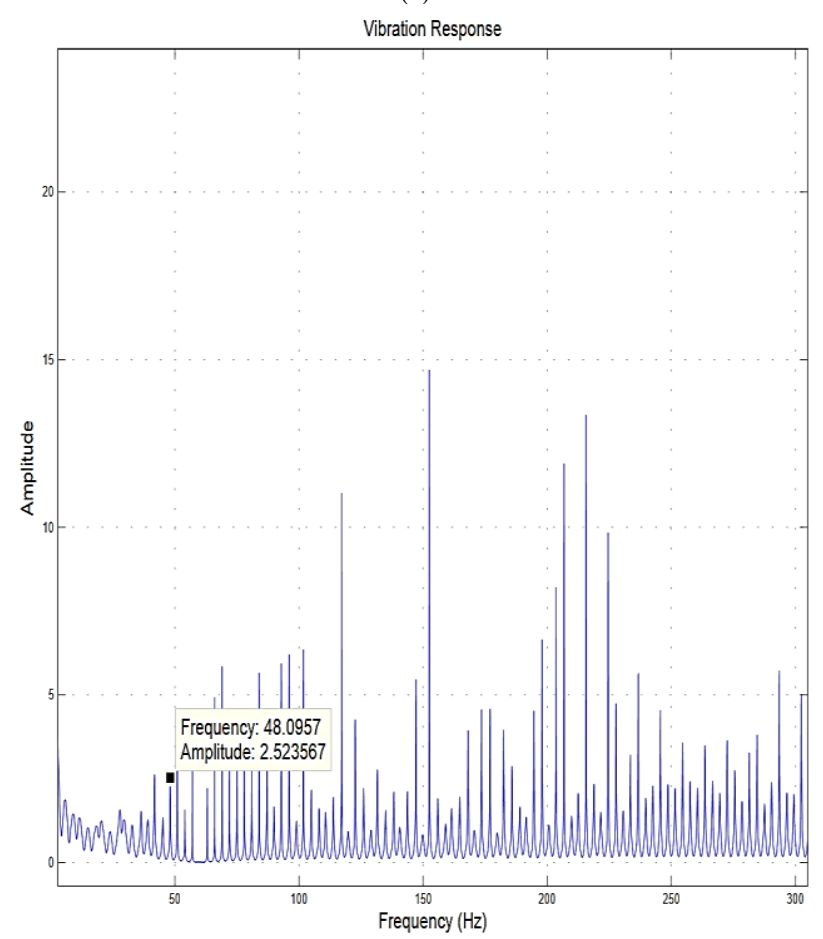

(d)

Fig. 4: Vibration response of 10-degree defective bearing at (a) 300; (b) 600; (c) 900; (d) 1200 RPM

Fig. 4 shows the vibration amplitude of the 10-degree defective ball bearing is obtained as $1.364 \mathrm{~m} / \mathrm{s}^{2}, 1.594 \mathrm{~m} / \mathrm{s}^{2}, 1.396 \mathrm{~m} / \mathrm{s}^{2}, 2.523$ $\mathrm{m} / \mathrm{s}^{2}$ at 300, 600, 900, $1200 \mathrm{RPM}$ respectively. There is a significant increase in the amplitude of vibration with an increasing the speed of the shaft. The peaks at BPFO have seen in the frequency spectrum is $12.451 \mathrm{~Hz}, 23.803 \mathrm{~Hz}, 36.132 \mathrm{~Hz}, 48.095 \mathrm{~Hz}$. From the theoretical model. The calculated ball pass frequency outer (BPFO) and the peaks generated in the frequency spectra are very close to each other this is clearly shown in table 2 . 


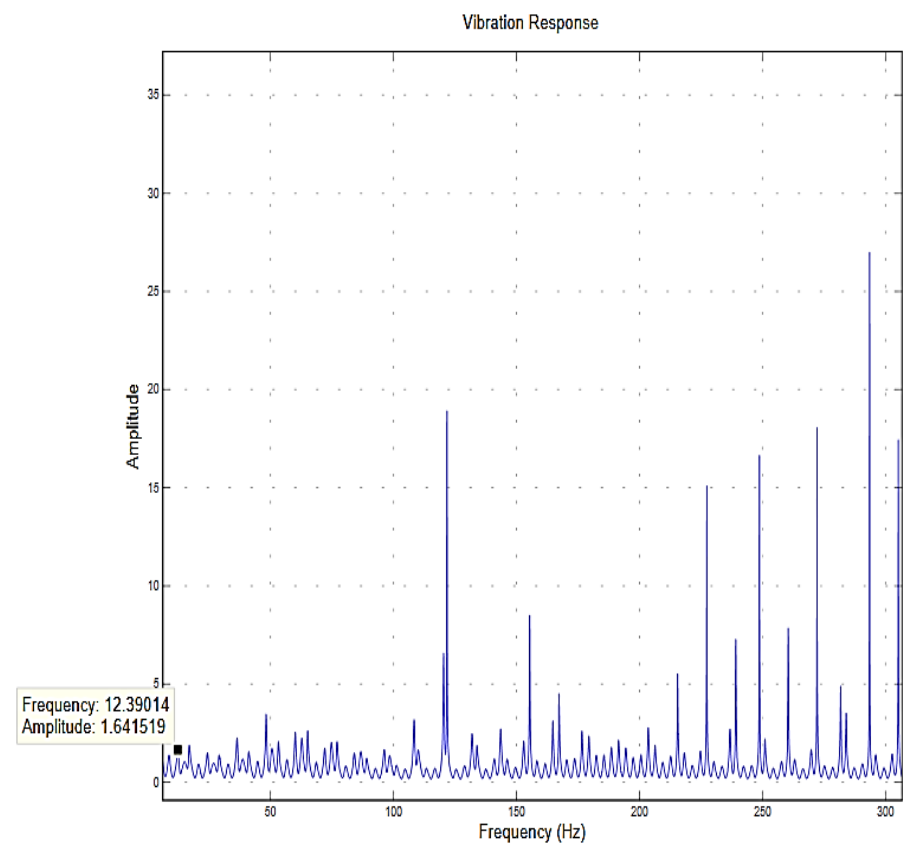

(a)

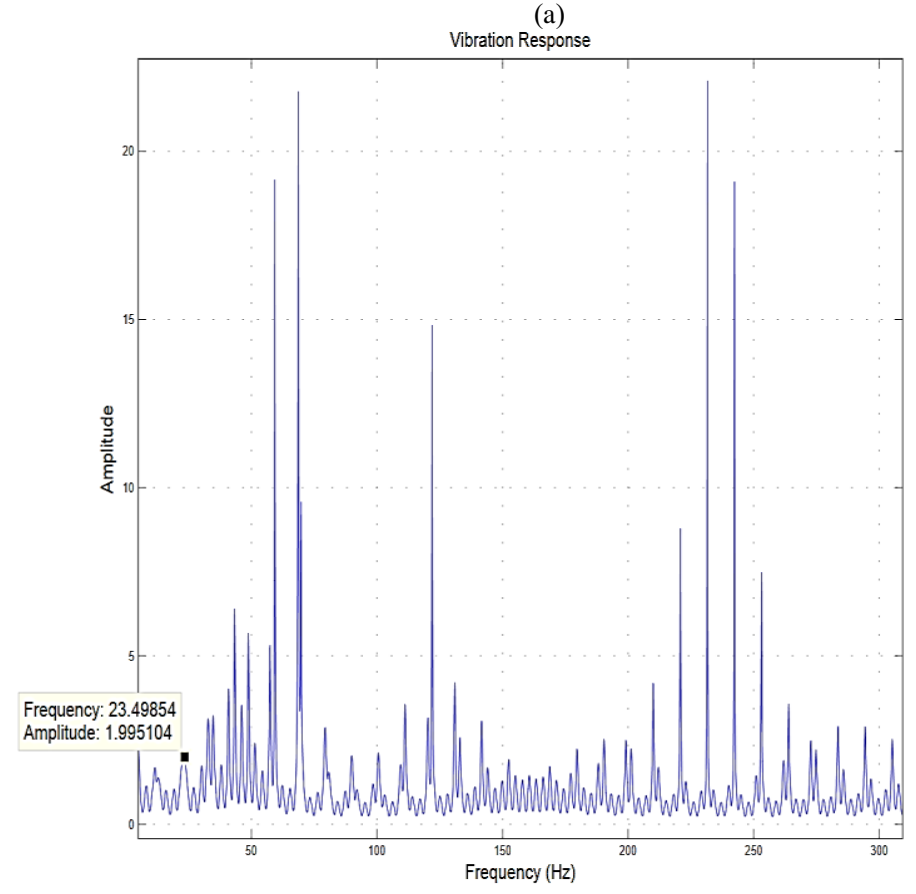

(b)

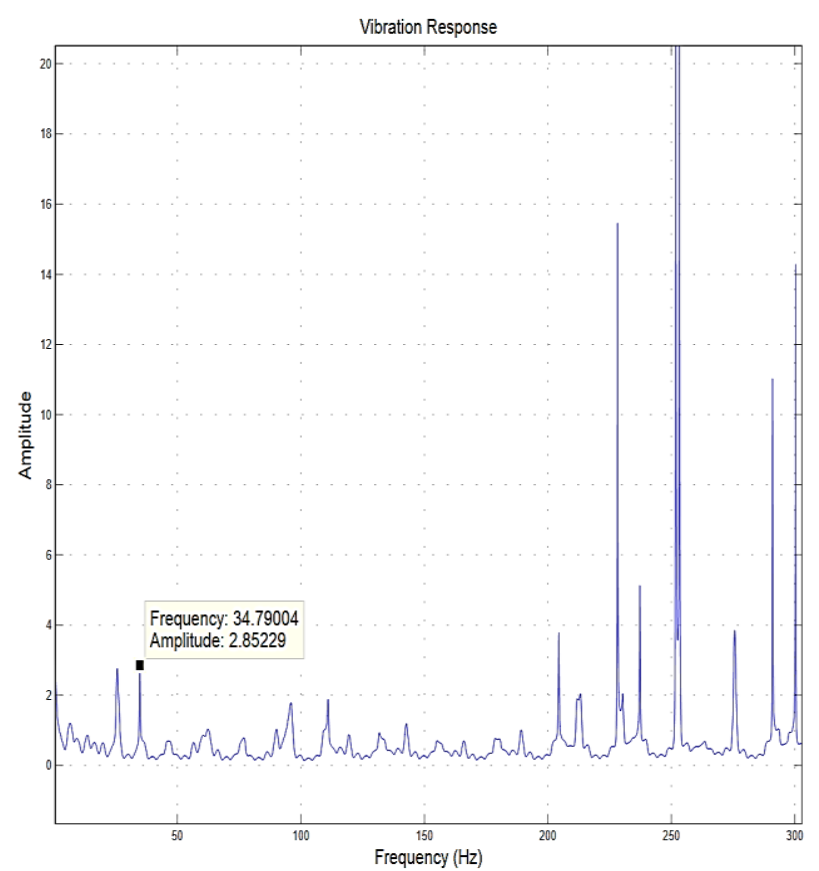

(c)

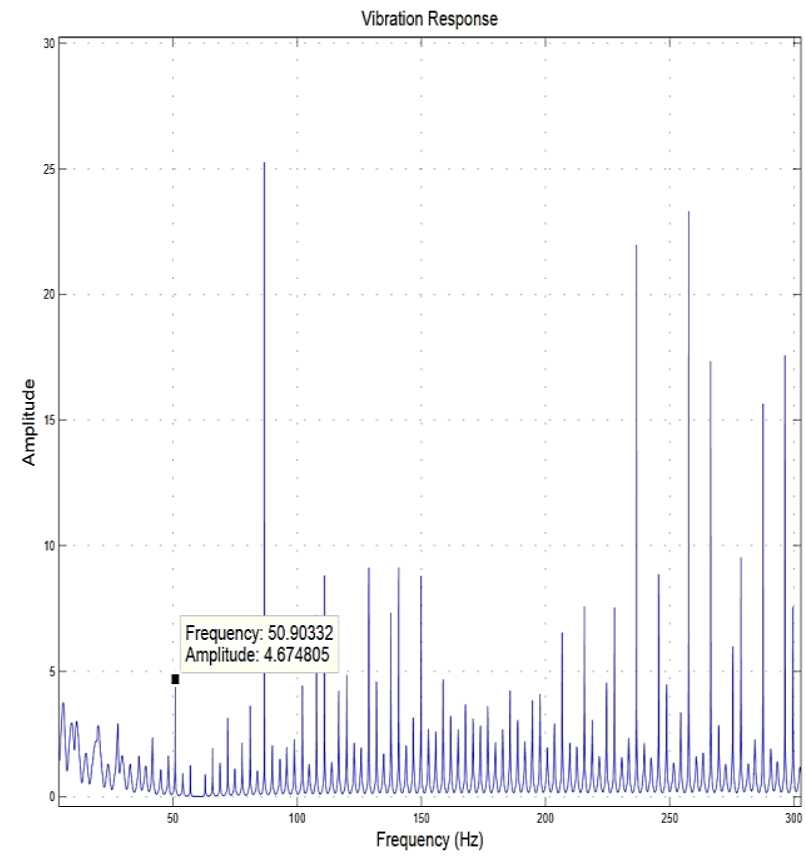

(d)

Fig. 5: Vibration response of 20-degree defective bearing at (a) 300; (b) 600; (c) 900; (d) 1200 RPM

Above fig. 5 shows the vibration amplitude of the 20-degree defective ball bearing is obtained as $1.641 \mathrm{~m} / \mathrm{s}^{2}, 1.995 \mathrm{~m} / \mathrm{s}^{2}, 2.852$ $\mathrm{m} / \mathrm{s}^{2}, 4.674 \mathrm{~m} / \mathrm{s}^{2}$ at 300, 600, 900, $1200 \mathrm{RPM}$ respectively. There is a significant increase in the amplitude of vibration with an increasing the speed of the shaft. The peaks at BPFO are seen in the frequency spectra is $12.390 \mathrm{~Hz}, 23.498 \mathrm{~Hz}, 34.790 \mathrm{~Hz}, 50.903 \mathrm{~Hz}$. from the theoretical model. The calculated ball pass frequency outer (BPFO) and the peaks generated in the frequency spectra are very close to each other this is clearly shown in table 2 .

Table 2 Comparison of vibration response for the healthy and defective ball bearing.

\begin{tabular}{|c|c|c|c|c|c|c|c|}
\hline \multirow{3}{*}{$\begin{array}{l}\text { Speed } \\
(\mathrm{rpm})\end{array}$} & \multirow{3}{*}{$\begin{array}{c}\text { Calculated } \\
\text { frequency }(\mathrm{Hz})\end{array}$} & \multirow{2}{*}{\multicolumn{2}{|c|}{ Healthy bearing response }} & \multicolumn{4}{|c|}{ Defective bearing response } \\
\hline & & & & \multicolumn{2}{|c|}{ 10-degree } & \multicolumn{2}{|c|}{ 20-degree } \\
\hline & & Frequency $(\mathrm{Hz})$ & Amplitude $\left(\mathrm{m} / \mathrm{s}^{2}\right)$ & Frequency $(\mathrm{Hz})$ & Amplitude $\left(\mathrm{m} / \mathrm{s}^{2}\right)$ & Frequency $(\mathrm{Hz})$ & Amplitude $\left(\mathrm{m} / \mathrm{s}^{2}\right)$ \\
\hline 300 & 12.07 & 13.12 & 0.0563 & 12.451 & 1.364 & 12.390 & 1.641 \\
\hline 600 & 24.15 & 24.10 & 0.0719 & 23.803 & 1.594 & 23.498 & 1.995 \\
\hline 900 & 36.22 & 37.04 & 0.0983 & 36.132 & 1.396 & 34.790 & 2.852 \\
\hline 1200 & 48.30 & 49.37 & 0.1071 & 48.095 & 2.523 & 50.903 & 4.674 \\
\hline
\end{tabular}


The peaks at BPFO are seen in the frequency spectrum is 12.451 $\mathrm{Hz}, 12.390 \mathrm{~Hz}$ for defective bearing and $13.120 \mathrm{~Hz}$ for healthy bearing obtained from the theoretical model while calculating ball pass frequency outer (BPFO) is $12.075 \mathrm{~Hz}$. For the speed $300 \mathrm{RPM}$. Hence the defective bearing rotating with 300 RPM, then the peak generated in frequency spectrum observed near to the calculated BPFO. Similarly, for the other speed 600, 900 and 1200 RPM generated peak nearest to the calculated BPFO see the table 2 for better understanding the results.

\section{Conclusion}

When a local defect grows, it becomes extended one and tends to spread over the track of the bearing race. There is a necessity to implement effective diagnosis of an extended fault in the ball bearing. Hence, the Theoretical model is developed to predict the vibration response of an extended defect in the outer race of the ball bearing.

As discussed in the above section the model response of healthy bearing is obtained $0.0563 \mathrm{~m} / \mathrm{s}^{2}, 0.07193 \mathrm{~m} / \mathrm{s}^{2}, 0.0983 \mathrm{~m} / \mathrm{s}^{2}, 0.1071$ $\mathrm{m} / \mathrm{s}^{2}$ at $300,600,900,1200 \mathrm{RPM}$. It is concluded that the amplitude of vibration of the healthy bearing increases with increasing speed. But the value of vibration amplitude is less than the defective bearing amplitude in the same range of speed.

The model response of an extended defect on the outer race of the ball bearing is obtained and discussed in the above section. The effect of speed and size of defects on the defective bearing shows the variation in frequency spectra as compared with the response of the healthy bearing. From the frequency spectra is clearly observed an increasing the speed of the defective bearing increases the vibration amplitude. Again, observe that the vibration amplitude increases with increasing the defect size.

The performance of the model has been confirmed by obtaining peaks of vibration amplitude in the healthy and defective ball bearing close to the calculated BPFO in frequency charts. The forecast of actual estimation of amplitude vibration isn't possible with this model because the difficulties occur while considering the rotor bearing system. Hence, defect size and speed are the affecting values to cause vibration of the bearing.

\section{Acknowledgement}

I owe great thanks to as many people who helped and supported me during my dissertation work, from the bottom of my heart. Especially thank Prof. Sham Kulkarni sir, giving me proper guidance for completion of my expected work.

\section{References}

[1] R.K. Purohit and K. Purohit " Dynamic analysis of ball bearing with an effect of preload and number of balls." Applied Mechanics and Engineering, 2006, volume /11 no.1, pp 77-91.

[2] Harris, T. A., 2001, Rolling Bearing Analysis, 3rd edition Wiley, New York. 19 Genta, G., 2004, On a Persistent Misunderstanding of the Role of Hysteretic Damping in Rotor Dynamics, ASME J. Vibr. Acoustic. 126, pp. 459Đ461.

[3] McFadden P. D, Smith J. D." Model for the vibration produced by a single point defect in a rolling element bearing."Journal of Sound and Vibration 1983; 96(1):69-82.

[4] McFadden P. D, Smith J. D. "Model for the vibration produced by multiple point defects in a rolling element bearing." Journal of Sound and Vibration 1984;98(2):263-73.

[5] Tandon N. Choudhury A. "An analytical model for the prediction of the vibration response of rolling element bearings due to a localized defect." Journal of Sound and Vibration 1997; 205(3):275-92.

[6] Tandon N, Choudhury A. "A theoretical model to predict vibration response of rolling bearings to extended defects under radial load. "Journal of Vibrations and Acoustics" 1998; 120:214-20.

[7] N. Tandon and A. Choudury, "Vibration response of rolling element bearings in rotor bearing system to a local defect under radial load." Journal of Tribology, 252/ Vol. 128, (2006)
[8] M.S. Patil et.al. "A theoretical model to predict the effect of the localized defect on vibrations associated with ball bearing," International Journal of Mechanical Sciences 52 (2010) 1193-1201.

[9] V.N. Patel, et al. "Vibration studies of dynamically loaded deep groove ball bearings in presence of local defects on races," precede Engineering 64 (2010) 1582-1591.

[10] Jairo A. Grajales, Juan F. Lopez " Ball bearing model: Development and experimental validation," Ingemeriay competitive idea volume $16,2 \mathrm{p}, 279-288$ (2014)

[11] Vikram V. Nagale and M. S. Kirkire, "A Mathematical Model to Determine Sensitivity of Vibration Signals for Localized Defects and to Find Effective Number of Balls in Ball Bearing," 2014 IJEDR Volume 2, Issue 3 | ISSN: 2321-9939

[12] N. Sawalhi and R.B. Randall, "Simulation of the vibrations produced by extended bearing faults in gearboxes", Proceedings of ACOUSTICS, 2006, pp. 541-548.

[13] Dick Petersen Sarabjeet singh," Analysis of bearing stiffness variations, contact forces and vibrations in a radially loaded double row rolling element bearings with raceway defects." Mechanical system and signal processing, http://dx.doi.org/10.1016/j.ymssp. 2014.04.014 